\title{
Absolute Determination of the Electrochemical Equivalent and the Atomic Weight of Zinc I. Method, Apparatus, and Preliminary Experiments
}

\author{
George Marinenko \\ Institute for Materials Research, National Bureau of Standards, Washington, D.C. 20234 \\ and
}

The American University, Washington, D.C. 20016

and

Robert T. Foley

The American University, Washington, D.C. 20016

\begin{abstract}
(August 28, 1975)
The use of a specially designed coulometer and a high accuracy coulometric circuit resulted in the accurate measurement of the electrochemical equivalent and atomic weight of zinc. The experimental conditions to make possible the final precise and accurate measurements were established. These include a study of mechanical losses from the anode during the electrolysis and the corrosion of zinc in various media used in the determination. The effects of both of these sources of error may be controlled. Mechanical losses are minimized when an amalgamated electrode is used; corrosion. when an amalgamated electrode is used in an air free system. An electrolyte, 25 wt. percent $\mathrm{NH}_{4} \mathrm{Cl}$ and 3 molal $\mathrm{ZnCl}_{2}$. was used in these determinations. This report presents the account of research which was prerequisite to subsequent accurate determination of the electrochemical equivalent and the atomic weight of zinc.
\end{abstract}

Key words: Atomic weight: coulometry; electrochemical equivalent; zinc atomic weight.

\section{Introduction}

The 1967 Report of the International Commission on Atomic Weights states that today virtually all data upon which atomic weights can be based are furnished by mass spectrometric measurements of "absolute" isotopic composition [1]. ${ }^{1}$ This observation of the Commission can be viewed in two ways. The first view is that the "state-of-the-art" of mass spectrometry has attained a level of sophistication unmatched by other methods potentially useful for the determination of atomic weights. The second view is that scientists in other areas of accurate measurement lack the incentive to involve themselves in this exacting yet significant work. Perhaps both factors are responsible for the existing situation. In any case the state of affairs is

'Figures in brackets indicate the literature references at the end of this paper. not very desirable. Determination of the constants of nature should be performed by a variety of methods, since it is clear that each method will invariably have some (though they may be extremely small) systematic errors. Determination of physical constants by several independent methods will, at least in principle, avoid some of these errors.

Prior to this work the accepted value of the atomic weight of zinc was $65.37 \pm 0.03[1,2]$. The above value was based on combining weight ratios of $\mathrm{ZnCl}_{2} / 2 \mathrm{Ag}$ [3], $\mathrm{ZnCl}_{2} / 2 \mathrm{AgCl}$ [3], $\mathrm{ZnBr}_{2} / \mathrm{Zn}$ [4], and $\mathrm{ZnCl}_{2} / \mathrm{Zn}$ [5]. Two mass spectrometric determinations of the isotopic abundances $[6,7]$ yielded a significantly different value for the atomic weight of zinc but since they were conducted without "absolute" calibration of the instruments the Commission recommended retaining the chemically determined value [1]. Zinc, which has five naturally occurring isotopes, presents a formidable problem for "absolute" calibration of mass spectrom- 
eters. Five separate $\mathrm{Zn}$ isotopes of considerable isotopic purity (99.9 percent of better) would be required. Moreover, a high precision method would also be required for analysis of these isotope solutions and subsequent preparation of known, requisite isotope mixtures for calibration of mass spectrometers [8-15]. The largest number of isotopes handled in this manner thus far in the determination of atomic weights is four. This was done for chromium [14].

Thus, at the start of this investigation there existed a divergence in the reported values for the atomic weight of zinc. It was important that this divergence be resolved since for many of the other elements the uncertainties in the atomic weights are of the order of 0.001 , or one order of magnitude less than that of zinc.

The suitability of electrochemical methods for the determination of atomic weights was implied in the original work of Faraday, and the explicit utilization of Faraday's laws for the determination of atomic weights was recognized very early in the development of quantitative electrochemistry. Thus, for example Laird and Hulett state [16]:

\footnotetext{
"Faraday's law, that a definite quantity of electricity is associated with one gram equivalent of any ion, is, as far as we hinow, strictly accurate, probably as accurate as the law of conservation of mass. There is evidence that not even as small a quantity of electricity as $10^{-16}$ coulomb passes from an electrolyte to and electrode without a corresponding chemical change taking place.
}

Using electrolytic deposition of $\mathrm{Cd}$ in series with a silver coulometer, Laird and Hulett were able to obtain precise $\mathrm{Cd} / \mathrm{Ag}$ ratios, and by using the accepted value for the atomic weight of silver they calculated the atomic weight of cadmium. A similar approach was used by Gladstone and Hibbert earlier [17] for the determination of $\mathrm{Zn} / \mathrm{Ag}$ and $\mathrm{Zn} / \mathrm{Cu}$ ratios, and consequently, the atomic weight of zinc. Unfortunately, we now know that silver deposition coulometers and copper coulometers, though precise, are not accurate due to the variation of the amount of occluded mother liquor in the deposit. This aspect of silver deposition coulometers has been discussed by Hamer [18]. A more direct approach to the determination of the electrochemical equivalent is through the use of absolute current and time measurement, employed by Craig and coworkers [19] in the determination of the electrochemical equivalent of silver and the Faraday and by Marinenko and Taylor in the determination of electrochemical equivalents of benzoic acid and oxalic acid $\lceil 20]$.

The difference between chemical values for the atomic weight of zinc (65.37) and the value obtained mass spectrometrically (65.39) is of the order of 0.03 percent. The atomic weight obtained by the electrochemical method was expected to have an uncertainty of 0.003 percent, one order of magnitude smaller than the existing uncertainty in the atomic weight of zinc. The significance of such an improvement in a constant of nature, as important as an atomic weight, is selfevident.
The earlier published paper [25] contains only a small fraction of data obtained in this research. This paper and the following [26] contain a complete account of the research conducted with the objective of determining accurately the electrochemical equivalent and the atomic weight of zinc.

This first paper describes the method, apparatus, and certain critical preliminary experiments which provided the basis for the determinations. The experimental study of the material treatment, electrode fabrication and handling, corrosion in air as well as in electrolyte solutions is described below.

\section{Experimental Procedures}

\subsection{The Method}

The method used involved the determination of the zinc dissolved anodically during the passage of a constant electrical current through the following electrochemical cell:

$\mathrm{Zn}(\mathrm{Hg}) \mid \mathrm{ZnCl}_{2}$ (3 m. aq). $\mathrm{NH}_{4} \mathrm{Cl}(25 \mathrm{wt} \%$. aq) $\mid \mathrm{Zn}(\mathrm{Hg})$.

The anodic reaction is

$$
\mathrm{Zn}(\mathrm{Hg}) \rightarrow \mathrm{Zn}^{++}+\mathrm{Hg}+2 e ;
$$

and the accompanying cathodic reaction is simply the reverse of reaction (1):

$$
\mathrm{Hg}+\mathrm{Zn}^{++}+2 e \rightarrow \mathrm{Zn}(\mathrm{Hg}) .
$$

In such a cell the composition of electrolyte remains unaltered throughout the whole experiment.

The passage of two Faradays of charge through the cell dissolves 1 mole of zinc from the zinc amalgam anode and deposits it on the cathode. The coulometric circuit employed in this work insures the passage of charge through the cell with 0.0002 percent accuracy. The coulometer used in this work is described in detail in a later section. A weighed zinc amalgam anode is suspended in the coulometer. A mercury pool cathode is located at the bottom of the coulometer. A ground glass flat joint in the coulometer is provided for insertion of a porous membrane filter which is used in some experiments to establish the existence or the absence of any significant fall-off of the material from the anode in the course of its electrochemical dissolution. The electrolyte is deaerated and a nitrogen atmosphere is maintained in the coulometer throughout the experiment.

Zinc anodes are weighed by substitution on a 20 g-capacity microbalance. The uncertainty of the mass measurement process (standard deviation) is $3 \times 10^{-6} \mathrm{~g}$.

A constant current of known magnitude is passed through the coulometer for a precalculated period of time sufficient to produce a desired change in mass of the anode, approximately equal to the mass of a single weight in the calibrated set of weights. After termination of electrolysis, the zinc anode is carefully 
removed from the coulometer, washed first in 0.1 molar $\mathrm{NH}_{4} \mathrm{Cl}$ solution and then in hot distilled water, dried and reweighed. Appropriate corrections for the effects of buoyancy of air are applied. Thus the charge to mass ratio can be readily computed.

\subsection{Coulometric Circuit}

The work described here was performed by constant current coulometry. In coulometry the following parameters are measured: electric charge consumed in performing electrochemical conversion and mass of substance involved. Since

$$
Q=\int_{0}^{\prime} i d t
$$

and $i=$ constant, the integral reduces to

$$
Q=i t
$$

Thus the measured electrical parameter, requiring accurate control, is current. In addition it is necessary to measure accurately the time in the course of which the electrical current flows through the coulometric electrolysis cell. The schematic diagram of the coulometric circuit is shown in figure 1.

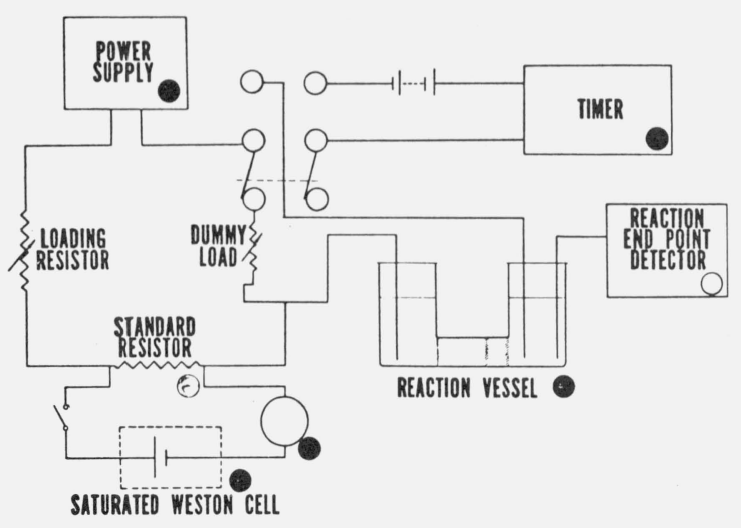

FIGURE 1. The schematic diagram of the coulometric circuit.

The circuit consists of a high precision constant current power supply, an accurate current comparison system, the necessary current stabilization resistors, the timing circuit and the coulometric reaction vessel, the electrolysis cell.

Power Supply. The instrument used in this work to power the coulometric circuit is a Princeton Applied Research regulated dc constant voltage and constant current power supply, Model TC-602CR. ${ }^{2}$ In the constant current mode of operation its output can be varied from 0 to $2 \mathrm{~A}$, provided the resistance of the

2 Certain commercial materials and equipment are identified in this paper in order to adequately specify the experimental procedure. In no case does such identification imply recommendation or endorsement by the National Bureau of Standards, nor does it imply that the material or equipment identified is necessarily the best available for the purpose. external load (the coulometric circuit) does not exceed the value limited by the maximum voltage output capability of the power supply, namely $60 \mathrm{~V}$. Thus the power supply can control accurately a constant current of 1 A with external loading up to $60 \Omega$.

The output current is selected by means of a fiveplace stepwise Kelvin-Verley divider with an additional continuously variable vernier slidewire, resulting in 0.0001 percent adjustable resolution in the output. The long-term stability of the output of the power supply (the constancy of current) is on the order of 0.001 percent per $8 \mathrm{~h}$ as determined by the manufacturer and verified experimentally in our laboratory. The load regulation (from no load to full load) and the line regulation (for $10 \%$ line voltage fluctuations) is 0.0001 percent. The ripple component (at any load) i.e., the combined effects of all ac components appearing in the output, is less than $50 \mu \mathrm{V}$ rms. This, of course, means that it is highly desirable to operate the power supply into a load of such magnitude that virtually full capability of the power supply to generate a given value of the current is utilized.

For this reason, as is indicated on the circuit diagram, an auxiliary variable loading resistance is incorporated into the coulometric circuit.

To minimize the time of recovery of the power supply to the preselected current value when the coulometer switch is turned on, a second set of resistors simulating the resistance of the coulometer, is inserted into the circuit. It is labeled "dummy load" on the schematic circuit diagram. Thus, the power supply always operates into essentially the same load, with the exception of the time of flight of the coulometer switch at the start and at the end of the experiment. This switching time is on the order of $0.02-0.03 \mathrm{~s}$.

Current comparator. The most commonly used method for accurate current measurement is a comparison method in which Ohm's law is utilized in its exact form. By Ohm's law

$$
i=\frac{1}{R} V
$$

i.e., the current flowing in an electrical circuit is proportional to the applied voltage and $1 / R$ is the proportionality constant. Thus, if one passes a current through an accurately calibrated resistor and measures accurately the voltage drop across that resistor one can readily compute the value of current. The most direct way of making an accurate current comparison is to make it of such magnitude that the $i R$ drop across the standard resistor, through which this current flows, is virtually equal to the voltage of a standard cell (in our case a saturated Weston cell). The difference between the $i R$ drop and the voltage of the standard cell is measured by means of a high input impedance null detector. The high impedance of the null detector is a prerequisite condition for such a measurement since otherwise appreciable current can flow in the comparator circuit at such times when an imbalance exists between the $i R$ drop and the voltage of the stand- 
ard cell. The passage of current through the standard cell is of course not permissible. If current is passed through the cell it becomes polarized and its emf departs from its equilibrium value. Following polarization, standard cells require long periods of time to recover to the equilibrium state and in fact permanent damage to the cells due to polarization is not uncommon [21].

For these experiments a Leeds and Northrup electronic d-c null detector model 9834 was used. Its input impedence is $4 \times 10^{4} \Omega$. Thus if the imbalance between the $i R$ drop across the standard resistor and the emf of the standard cell $(\sim 1.018 \mathrm{~V})$ is 0.1 percent $\left(10^{-3} \mathrm{~V}\right)$ the current in the comparator circuit will be $2.5 \cdot 10^{-8} \mathrm{~A}$ or $0.025 \mu \mathrm{A}$ which is negligible. Furthermore, immediately after a mismatch between the $i R$ drop and the standard cell voltage is noticed the output of the power supply is adjusted until a perfect balance is achieved (within $1 \mu \mathrm{V}$ ). The accurate value of current is computed from the calibration values of the standard resistor and the emf of the saturated standard Weston cell. National Bureau of Standards (NBS) type calibrated standard resistors were used in all experiments. Their resistance values are known to \pm 0.0001 percent. Since the resistor wire in NBS standard resistors is manganin its temperature coefficient near $25{ }^{\circ} \mathrm{C}$ is about 0.0005 percent per ${ }^{\circ} \mathrm{C}$. In order to insure accurate current measurement, standard resistors were kept in an oil bath, thermostated to better than $0.1{ }^{\circ} \mathrm{C}$ thus insuring accuracy in the resistance value of better than 0.0001 percent [22].

Saturated Weston cells have a much larger temperature coefficient (at $35{ }^{\circ} \mathrm{C}$ it is on the order of 0.005 $\%$ per ${ }^{\circ} \mathrm{C}$ ). Consequently they were maintained in an air thermostat, the temperature of which was maintained constant near $35^{\circ} \mathrm{C}$ within $0.01{ }^{\circ} \mathrm{C}$, again insuring better than 0.0001 percent accuracy in the value of the emf of the standard cell [21]. Thus the value of the current in all experiments was known to better than 0.0001 percent.

Timer. Since the laboratory in which experiments were conducted has a $100 \mathrm{kHz}$ standard frequency outlet, the accuracy of which is better than 1 part in $10^{12}$, the simplest way to measure the time was to scale the frequency between the time that the current is diverted to flow through the coulometer and the time that it is turned off (diverted to flow through the dummy resistance). This provided $10^{5}$ counts on the scaler per second, or the resolution of time interval to the nearest $10 \mu \mathrm{s}$.

Mass Measurement. A 20-gram capacity Mettler microbalance was used for all mass measurements. To make mass measurements of the highest accuracy substitution weighing must be performed. The standard deviation of the mass measurement operation, established over a number of years in this laboratory amounts to $3 \times 10^{-6} \mathrm{~g}$.

\subsection{The Coulometer}

The final design of the coulometer was achieved after many trial attempts with various designs. The coulometer (fig. 2) consists of four segments. The lower

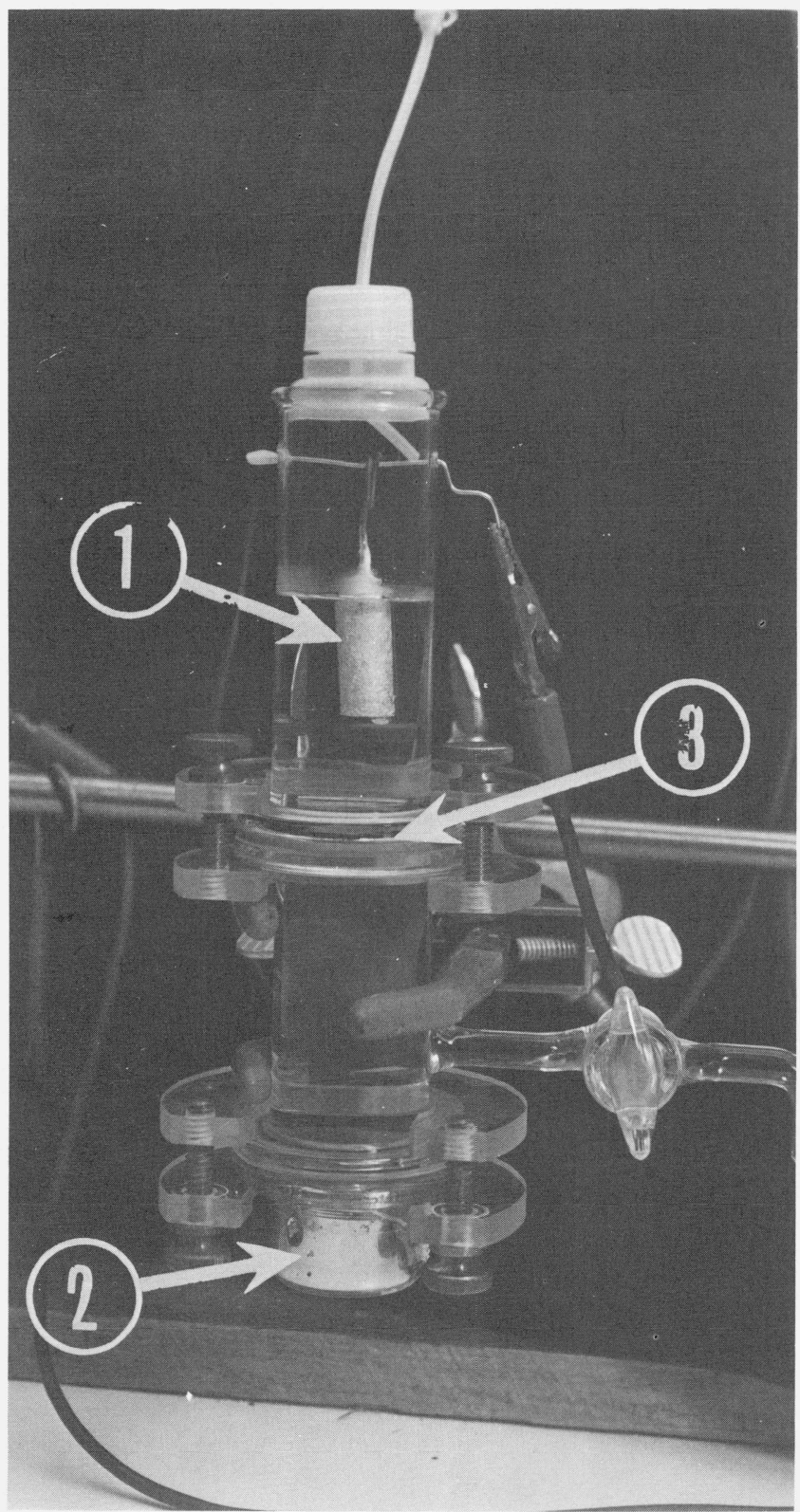

FIGURE 2. Coulometer for the determination of the atomic weight of zinc.

1-zinc amalgam anode; 2 -mercury pool cathode; 3 -ground glass flat joint.

part is the cathode cup containing a ground glass flat surface to mate with the second part and a platinum contact sealed into the side. The original intent was to use the lower cup for the gravimetric determination of zinc, deposited cathodically into the mercury pool. Unfortunately, cathodic deposition and weighing of zinc for the purpose of determining the electrochemical equivalent was not sufficiently quantitative to produce significant results. One of the reasons is growth of zinc dendrites, which are difficult to handle, wash and weigh with a high degree of accuracy. 
The second segment of the cell contains stopcock provisions in order to allow drainage of the electrolyte above that point. The upper surface of the second segment is the flat ground glass surface designed to mate with the third segment of the cell. This arrangement enables one to insert a previously weighed filter between the ground glass surfaces during assembling of coulometer. Filters are used to establish the existence or the absence of any material flaking from the anode.

The third segment contains provisions for a platinum hang wire upon which the zinc anode is suspended, making an electrical contact with the constant current circuitry.

Finally, the uppermost segment of the cell is a cut-down polyethylene cap with a friction fitted polyethylene tube insert. This tube enables deaeration of the electrolyte in the cell and subsequent passage of the high purity nitrogen over the electrolyte in order to reduce spontaneous corrosion of zinc.

In the upright design coulometer used in this work, a Millipore filter was inserted between the second and third segments of the cell. Thus the deposit could be accumulated directly upon the filter. By opening the stopcock in the second segment of the cell one could easily drain the electrolyte through the Millipore filter, wash it as many times as required, disassemble the cell, dry and reweigh the filter. Thus the amount of deposit on it could be determined.

Another advantage of the coulometer used in this work is that the path length of the current in the electrolyte is relatively short as compared with the coulometer of Craig and coworkers [19] and therefore the resistance of the cell is quite low (the resistance of the cell filled with electrolyte was about $10 \Omega$ ). This allows passage of relatively large currents (e.g., 1 A) without any appreciable heating of the cell and without the requirement of having a power supply with a large voltage output.

\subsection{The Problem of Anodic Fall-Off}

The Millipore filter incorporated in the final improved design of the coulometer was intended to cope with the problem of undissolved material falling from the zinc anode during the passage of current. This addition to the coulometer came about in the following way. The initial experiment involved the use of a pure zinc anode. No precautions were taken to keep the air out of the cell. The passage of $101 \mathrm{~mA}$ current through the cell for a sufficient period of time dissolved $5.274 \mathrm{mmol}$ of zinc to produce a $345.6 \mathrm{mg}$ change in the mass of the zinc anode (corrected to the mass in vacuum). It was noted at the time that a significant amount of particulate matter was flaking from the anøde. The precipitate was collected and weighed. The weight of this deposit was $1.0 \mathrm{mg}$.

Using the value for the mass difference based only on the weight of anode before and after the experiment the computed atomic weight is 65.52 . This value is much too high and can be explained reasonably well by the weight loss due to flaking of the material from the anode. If one applies the correction on the basis of the collected particulate material $(1.0 \mathrm{mg})$ the change in mass of the anode becomes $344.6 \mathrm{mg}$ and the corrected atomic weight is 65.33 . This latter value is in closer agreement with the then recognized value (65.37).

It is not the numerical value obtained in this experiment but rather the observable flaking effect which is of significance. Since the amount of flaking is about 0.3 percent the anode material cannot be used in this form for accurate atomic weight determination. The experiment described above was repeated using a zinc anode amalgamated with high purity mercury. The apparent surface area of the electrode was $13 \mathrm{~cm}^{2}$. Here again the coulometer was operated in the air atmosphere.

Seven experiments were performed using a current of $101 \mathrm{~mA}$. The obtained data are summarized in table 1 .

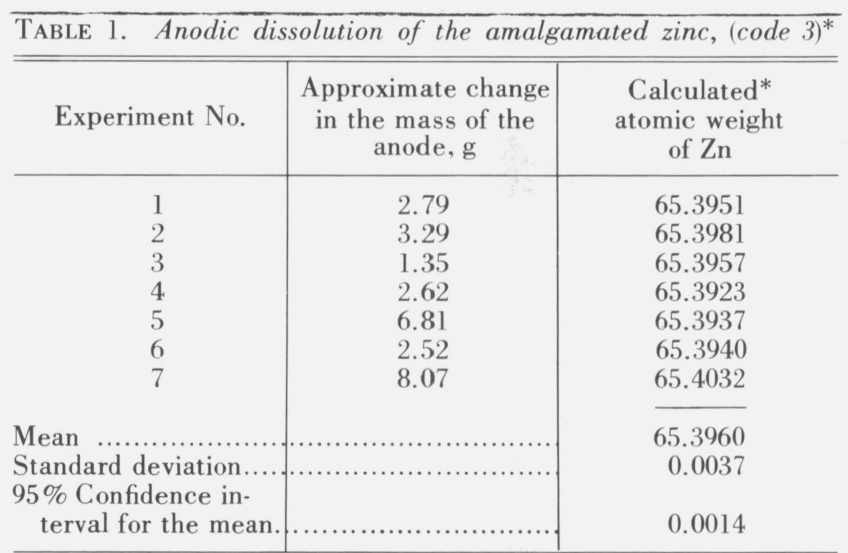

* No precautions were taken to exclude air from the cell, thus the results obtained here are biased by the amount proportional to the corrosion current in air saturated electrolyte. The area of the anode was $\sim 13 \mathrm{~cm}^{2}$.

The results of these experiments must be taken only as indicative and not definitive as far as the obtainable accuracy of the atomic weight of zinc is concerned. The experiments described later will in fact show that the presence of air in the electrolyte produces an undesirable effect as it increases the rate of spontaneous corrosion of zinc amalgam. Thus, the values obtained here are biased by the amount proportional to the corrosion current.

Under the experimental conditions used here no visible flaking of the material from the anode took place. The reproducibility of the results and the agreement of the computed value of the atomic weight with the accepted value were sufficient to warrant further serious effort to be made in improving the procedure and testing the accuracy of the results.

The absence of visible flaking does not necessarily prove that it does not take place. A more convincing proof of the nonexistence of flaking could be offered if the electrolyte were filtered after electrolysis and the amount of solid residue produced in the course of the electrolysis determined by weighing. This in fact was 
done in the determination of the electrochemical equivalent of silver and the value of the Faraday by Craig and coworkers [19]. They utilized an anodic silver coulometer, similar in principle to the one employed in this work. The anodic coulometer was chosen in favor of the cathodic silver deposition coulometer because it obviates mother liquor occulsion errors. At the same time it requires collection and weighing of material which flakes off in the course of the dissolution of the silver anode. In the case of silver, flaking off is quite significant (but not as significant as in the case of unamalgamated zinc). Craig et al. [19] took great care in transferring the contents of the anode compartment into Pyrex filtering crucibles, filtering it and determining the weight of the sediment. This procedure is rather time consuming and requires a great deal of manipulative practice and skill.

It therefore seemed desirable to design a coulometer which would eliminate the need for material transfer. Since no visible flaking from the amalgamated zinc anode took place it was suspected that perhaps particle size in this case is extremely small. It would therefore be desirable to filter the anolyte through a high efficiency filter. Membrane filters with $0.8 \mu$ pore size were used. Before the electrolyte was introduced into the coulometer it was filtered into a suction flask through the same type of a filter used in the coulometer. This was done to insure that no appreciable amount of solid could be introduced by the electrolyte. Therefore any increase in the mass of the filter in the coulometric cell must of necessity be attributed to the solid material flaking from the anode (located above the filter).

The lower part of the cell was filled with the electrolyte prior to the placement of the preweighed filter upon the ground glass surface. After the filter is satisfactorily seated upon the flat glass surface and adheres to the electrolyte beneath without any visible gas bubbles, the upper structure of the cell is put in place. The remaining part of the cell is then assembled, appropriately clamped, and the upper part filled with the electrolyte to the desired level.

Following the passage of the preselected amount of electric charge through the coulometer the electrolyte is drained through the stopcock. About $200 \mathrm{ml}$ of $0.1 \mathrm{M}$ $\mathrm{NH}_{4} \mathrm{Cl}$ solution is used to wash the filter followed by about $400 \mathrm{ml}$ of hot distilled water. The cell is then disassembled, the filter is dried at $50{ }^{\circ} \mathrm{C}$ in a drying oven for $1 \mathrm{~h}$, set into a disiccator (in which humidity was maintained at 50 percent) for $4 \mathrm{~h}$, then weighed.

In these experiments a second filter was placed in the cell, beneath the first one in a sandwich form. It served as a control filter. This was necessary because the mass of a filter varies from time to time depending on handling, extent of rinsing, etc. The use of a control filter minimizes the experiment-to-experiment variation.

The two filters used in the described experiments weighed approximately $0.70 \mathrm{~g}$ each. The data obtained in these experiments are given in table 2 . In the experiments in which current was passed through the coulometer the mean change of the mass of zinc anodes per experiment was $4.17 \mathrm{~g}$.

T'ABLE 2. Filtration of electrolyte after anodic dissolution of $\mathrm{Zn}$

\begin{tabular}{|c|c|c|}
\hline Experiment No. & $\begin{array}{l}\text { Change in mass of } \\
\mathrm{Zn}(\mathrm{Hg}) \text { anode } \\
\text { oxidized at } 500 \mathrm{~mA}^{*}\end{array}$ & $\begin{array}{l}\text { Normalized change } \\
\text { of mass (g) of top } \\
\text { Millipore filter }\end{array}$ \\
\hline 1 & \multirow{12}{*}{$\begin{array}{c}-* * \\
\lg (5800 \mathrm{~s}) \\
-* * \\
-* * \\
4 \mathrm{~g}(23200 \mathrm{~s}) \\
-* * \\
2 \mathrm{~g}(11600 \mathrm{~s}) \\
4 \mathrm{~g}(23200 \mathrm{~s}) \\
-* * \\
4 \mathrm{~g}(23200 \mathrm{~s}) \\
10 \mathrm{~g}(58000 \mathrm{~s}) \\
\ldots \ldots \ldots \ldots \ldots \ldots \ldots\end{array}$} & +0.000011 \\
\hline $\begin{array}{l}1 \\
2\end{array}$ & & -0.000041 \\
\hline 3 & & -0.000044 \\
\hline 4 & & -0.000042 \\
\hline 5 & & +0.000049 \\
\hline 6 & & -0.000156 \\
\hline 7 & & +0.000038 \\
\hline 8 & & -0.000145 \\
\hline 9 & & +0.000070 \\
\hline 10 & & -0.000008 \\
\hline 11 & & +0.000068 \\
\hline Mean. & & -0.000018 \\
\hline
\end{tabular}

* The electrolysis time is given in parenthesis.

**No current was passed through the cell, i.e., a blank experiment.

The changes in the mass of the membrane filter, $\left(\Delta m_{f}\right)$, are independent of the passage of charge and there appears to be no relationship between the mass of zinc dissolved and $\Delta m_{f}$. For example, in experiment 11 the mass of dissolved zinc is $10 \mathrm{~g}$ and $\Delta m_{f}=+68 \mu \mathrm{g}$, which is almost the same as in experiment $9\left(\Delta m_{f}=+\right.$ $70 \mu \mathrm{g}$ ), in which no coulometric dissolution of zinc was performed. The mean value of $\Delta m_{f}$ per gram of zinc dissolved (based on experiments 2, 5, 7, 10, and 11) is $1.6 \mu \mathrm{g}$.

For the purpose of statistical evaluation of the results and for making the comparison between the blank experiments and the experiments in which coulometric dissolution of zinc was performed it is more useful to compute the mean value of the change of mass of the filter per experiment. The overall mean $\Delta m_{f}$ per experiment including both the blank experiments and the coulometric experiments is $-18 \mu g$ (table 2). For coulometric experiments only, the mean value of $\Delta m_{f}$ is $-7 \mu \mathrm{g}$ per experiment. For experiments $(1,3,4,6,9)$ the mean $\Delta m_{f}$ is $-32 \mu \mathrm{g}$ per experiment.

The pooled standard deviation for the $\Delta m_{f}$ per experiment on the basis of the two sets of data (the blank experiments and the coulometric experiments) is $s=81 \mu \mathrm{g}$. Using this value of $s$ in conjunction with the 6 coulometric experiments the uncertainty in the mean change of mass of the filter per experiment is $s / \sqrt{ } n=38$ $\mu \mathrm{g}$. On this basis the mean value of $\Delta m_{f}$ does not produce a significant error.

Thus using the mean value of the mass of dissolved $\mathrm{Zn}(4.17 \mathrm{~g})$ and assigning the above computed uncertainty to the change of mass of the filter $(38 \mu \mathrm{g})$ one can safely conclude that within the limits of the uncertainty of the measurement the amalgamated zinc anodes undergo electrochemical dissolution without any detectable fall-off of material in the course of electrolysis. These data justified abandoning any further attempts to measure the material fall-off. 


\subsection{The Electrolyte}

The electrolyte used in final experiments was $25 \mathrm{wt}$ percent $\mathrm{NH}_{4} \mathrm{Cl}+3$ molal $\mathrm{ZnCl}_{2}$. The choice of these particular concentrations was not arbitrary. The optimum electrolyte for the coulometric experiments should meet several criteria: (a) it must nave low resistivity; (b) it must have sufficient concentration of $\mathrm{Zn}^{++}$to satisfy cathodic demand for deposition of $\mathrm{Zn}^{++}$ at large currents (up to 1 ampere); (c) it must dissolve $\mathrm{ZnCl}_{2}$ without any hydrolysis to $\mathrm{Zn}(\mathrm{OH})_{2}$. Criterion (c) is satisfied by using $\mathrm{NH}_{4} \mathrm{Cl}$ as the electrolyte. The presence of a large concentration of $\mathrm{ZnCl}_{2}$ fulfills criterion (b). Finally the actual choice of the specific concentrations was dictated by the resistivity data [23]. Tabulated data [23] show that 25 wt percent $\mathrm{NH}_{4} \mathrm{Cl}$ is virtually a saturated solution and its resistivity is the lowest; thus this is its optimum concentration.

\subsection{Electrode Construction}

Rectangular or cylindrical pieces of zinc were used for fabrication of electrodes. Cylindrical pieces were obtained either by transverse cutting of commercial zinc (which frequently comes in the shape of cylindrical rods) or the rods obtained during vacuum or air fusion of various zinc samples in Vycor tubes. Rectangular specimens were obtained by cutting originally large ingots of zinc on a mill with a tungsten carbide tool. After cutting, pieces of zinc were cleaned by etching in 1:1 Ultrex ${ }^{3} \mathrm{HNO}_{3}$. An approximately 2-mm

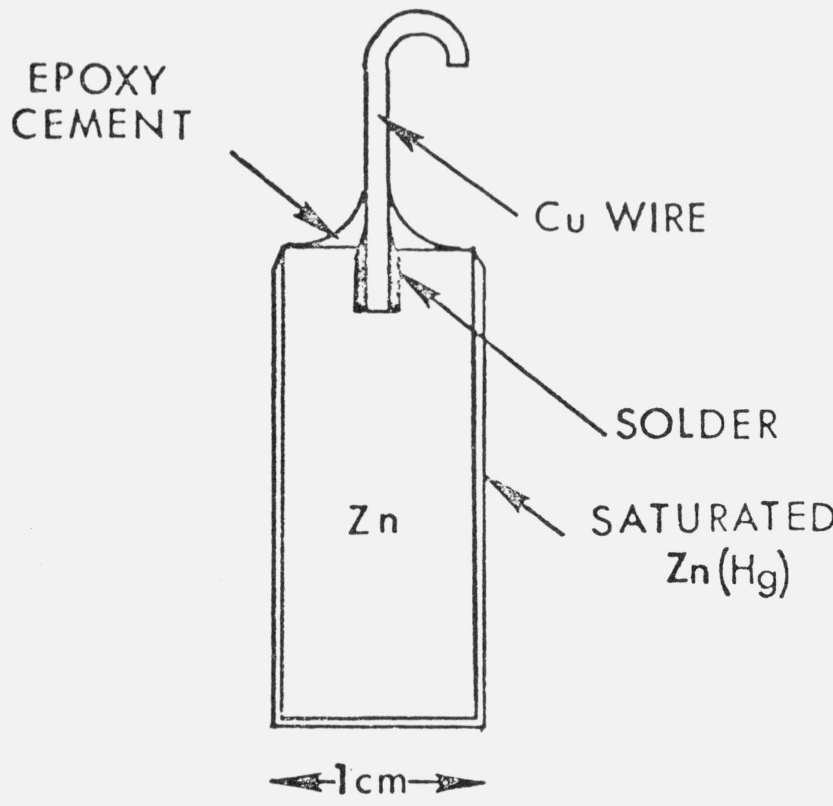

Figure 3. Construction of $\mathrm{Zn}(\mathrm{Hg})$ anode.

\footnotetext{
${ }^{3}$ Ultra-high purity material from J. T. Baker Chemical Co.
}

diameter hole was drilled in the upper surface of the electrode to a depth of about $5 \mathrm{~mm}$, figure 3 . A snugly fitting $\mathrm{Cu}$ wire coated on the end with a film of solder was inserted into the hole. A soldering gun was applied to the $\mathrm{Cu}$ wire unit the solder just softened and then removed quickly. This treatment provided for a reliable electrical contact between $\mathrm{Cu}$ and $\mathrm{Zn}$. The upper surface of the electrode along with about $1 / 2$ of the $\mathrm{Cu}$ wire lead were coated with epoxy cement and permitted to harden. The lower segment of the electrode was then cleaned again by partial immersion into $1: 1$ $\mathrm{HNO}_{3}$. Subsequently the zinc surface was amalgamated with high purity $\mathrm{Hg}$ by immersion. The electrode was then suspended in a specially designated and coded spot of an electrode storage-box made of Lucite. Each electrode was cleaned in $0.1 M \mathrm{NH}_{4} \mathrm{Cl}$ and washed with hot distilled water just prior to its use in the experiment.

\subsection{Stability of Zinc and Zinc Amalgam Anodes in Different Media}

In order to conclude that the change in mass of the anode is caused by the passage of electric current one must first of all prove that the mass of the anode is in fact invariant when such current is not passed through the system. Or, one must establish the stability of anodes in the media to which they will be exposed and determine to what extent the observed changes will affect the finally determined value of the atomic weight of zinc.

Zinc and zinc amalgam anodes of the same geometric configuration as used in the final experiments were investigated for stability in different media. These media are those in which the electrodes will reside in the course of the final experiments: (1) $0.1 \mathrm{M} \mathrm{NH}_{4} \mathrm{Cl}$; (2) 25 wt percent $\mathrm{NH}_{4} \mathrm{Cl}+3 \mathrm{~m} \mathrm{ZnCl}_{2}$; (3) distilled water; (4) air.

Eight electrodes, $10 \mathrm{~cm}^{2}$ in area, were fabricated in the same manner as the electrodes used in the final experiments. Four of these electrodes were amalgamated using dilute Ultrex $\mathrm{HNO}_{3}$ and high purity mercury, rinsed in $0.1 M \mathrm{NH}_{4} \mathrm{Cl}$ and hot distilled water, dried in air for $15 \mathrm{~min}$ and then weighed. The remaining four electrodes were left nonamalgamated. One of each kind of electrode was immersed into $\mathrm{NH}_{4} \mathrm{Cl}$ or $\mathrm{NH}_{4} \mathrm{Cl}$ $+\mathrm{ZnCl}_{2}$ solution or distilled water by suspending it on a support wire above a beaker containing the solution and left immersed for the desired period of time. Following the desired exposure time the electrodes were removed, washed in hot distilled water and reweighted in the manner described above. The electrodes suspended in air were first dipped into $0.1 \mathrm{M}$ $\mathrm{NH}_{4} \mathrm{Cl}$ solution then washed with hot distilled water, dried and weighted.

The rate of mass changes of $\mathrm{Zn}(\mathrm{Hg})$ and pure $\mathrm{Zn}$ electrodes during the exposure to the different media are shown in table 3.

The interpretation of these tabular data leads to several conclusions.

Firstly, in all media the rate of corrosion of $\mathrm{Zn}(\mathrm{Hg})$ electrodes is lower than that of pure $\mathrm{Zn}$ electrodes. 
TABLE 3. The rate of mass change of $\mathrm{Zn}(\mathrm{Hg})$ and $\mathrm{Zn}$ per unit area

Rate of mass change per unit area $\mu \mathrm{g} \mathrm{cm}{ }^{-2} \mathrm{~h}^{-1 *}$

\begin{tabular}{|c|c|c|}
\hline Medium & $\mathrm{Zn}(\mathrm{Hg})$ & $\mathrm{Zn}$ \\
\hline $\mathrm{NH}_{4} \mathrm{Cl}(0.1 M)$ & -2.5 & -7.7 \\
\hline $\begin{array}{l}\mathrm{NH}_{4} \mathrm{CI}(2 \mathrm{~b} \text { wt percent }) \\
+3 \text { molal } \mathrm{ZnCl}_{2} \\
\text { Distilled water }\end{array}$ & $\begin{array}{l}-1.7 \\
+1.6\end{array}$ & $\begin{array}{r}-8.0 \\
+2.6\end{array}$ \\
\hline
\end{tabular}

*The estimated uncertainty in these measurements is $0.5 \mu \mathrm{g}$ $\mathrm{cm}^{-2} \mathrm{~h}^{-1}$.

Secondly, the rate of corrosion of $\mathrm{Zn}(\mathrm{Hg})$ electrodes is lower in a $\mathrm{NH}_{4} \mathrm{Cl}$ solution containing 3 molal $\mathrm{ZnCl}_{2}$ than in a $\mathrm{NH}_{4} \mathrm{Cl}$ solution alone. This can occur for two reasons: (a) the addition of $\mathrm{Zn}^{++}$(the corrosion product) by the law of mass action decreases the driving force of the reaction; (b) corrosion of $\mathrm{Zn}(\mathrm{Hg})$ involving oxygen will be decreased, since the increase of the ionic strength of solution decreases the solubility of oxygen in aqueous solutions [24]. Hence, a decrease in the rate of corrosion results.

Thirdly, the rate of corrosion of nonamalgamated zinc remains virtually the same in the two electrolytes ranging from -7.7 in $\mathrm{NH}_{4} \mathrm{Cl}$ solution to $-8.0 \mu \mathrm{g} \mathrm{cm}^{-2}$ $\mathrm{h}^{-1}$ in $\mathrm{NH}_{4} \mathrm{Cl}+\mathrm{ZnCl}_{2}$ solution. On the other hand the rate of corrosion of amalgamated zinc is -2.5 and $-1.7 \mu \mathrm{g} \mathrm{cm}^{-2} \mathrm{~h}^{-1}$ in the above two solutions respectively. Thus, the lower solubility of oxygen in the solution of higher ionic strength has no effect on the rate of corrosion of nonamalgamated zinc. What is more important in this case is the slight decrease of $\mathrm{pH}$ due to hydrolysis of $\mathrm{ZnCl}_{2}$, which in fact accelerates the rate of corrosion. The $\mathrm{pH}$ of the $\mathrm{NH}_{4} \mathrm{Cl}$ solution was 4.70 while the $\mathrm{pH}$ of the 25 wt percent $\mathrm{NH}_{4} \mathrm{Cl}$ +3 molal $\mathrm{ZnCl}_{2}$ was 3.72 . From table 3 it is clear that in $\mathrm{NH}_{4} \mathrm{Cl}$ and $\mathrm{NH}_{4} \mathrm{Cl}+\mathrm{ZnCl}_{2}$ solutions the constancy of weight of $\mathrm{Zn}(\mathrm{Hg})$ electrodes is a factor of 3 to 4 greater than that of nonamalgamated electrodes. Using Faraday's law and taking the atomic weight of zinc as 65.4 , the computed corrosion current density, $J_{\text {corr }}$, for amalgamated zinc in 25 wt percent $\mathrm{NH}_{4} \mathrm{Cl}+3$ molal $\mathrm{ZnCl}_{2}$ (the electrolyte which was selected for final experiments) is $1.3 \times 10^{-3} \mathrm{~mA} \mathrm{~cm}^{-2}$. It must be kept in mind, however, that this corrosion current is obtained with air-saturated solutions. When solutions are deaerated and an inert atmosphere is maintained above them a corresponding decrease of the corrosion current on the $\mathrm{Zn}(\mathrm{Hg})$ surface is observed.

The corrosion in $\mathrm{NH}_{4} \mathrm{Cl}$ solution was measured because it was used as one of the wash solutions for the electrodes in the final experiments. In the course of 5-10 min of washing time no significant weight loss is encountered. Using a $10 \mathrm{~cm}^{2}$ electrode as a typical example and assuming $15 \mathrm{~min}$ wash time in $0.1 \mathrm{M}$ $\mathrm{NH}_{4} \mathrm{Cl}$ solution the total anticipated weight loss will be about $6 \mu \mathrm{g}$.

Distilled water was tested for the same reason as the $0.1 \mathrm{M} \mathrm{NH}_{4} \mathrm{Cl}$ solution. It is used for the final rinsing of electrodes. As one would expect, both $\mathrm{Zn}$ and $\mathrm{Zn}(\mathrm{Hg})$ electrodes gain weight upon immersion into distilled water due to formation of water insoluble hydrated $\mathrm{ZnO}$. The rate of formation of $\mathrm{ZnO}$ is somewhat greater (by about a factor of 2) on a pure $\mathrm{Zn}$ surface than on $\mathrm{Zn}(\mathrm{Hg})$.

On examining the weight change data for the electrodes stored in air it became quite apparent that within the experimental error the weight loss is not a function of exposure time. Since the weight loss itself results from the dissolution of $\mathrm{ZnO}$, formed on the electrode surface during exposure to air, one must conclude that the oxide film thickness on electrodes, stored in air, reaches a constant value (parabolic behavior). The limiting value (after $264 \mathrm{~h}$ of exposure) is $16.0 \mu \mathrm{g} \mathrm{cm}^{-2}$. A $28-\mathrm{h}$ exposure produces $10.9 \mu \mathrm{g} \mathrm{cm}^{-2}$ of $\mathrm{ZnO}$, indicating that the limiting value is approached asymptotically. Final experiments in which the weighing operation required approximately $2 \mathrm{~h}$ substantiated this value. The amount of $\mathrm{ZnO}$ formed in the course of weighing of electrodes in the final experiments was found to be $9.1 \mu \mathrm{g} \mathrm{cm}^{-2}$.

It is interesting to note that in distilled water the formation of hydrated $\mathrm{ZnO}$ on $\mathrm{Zn}(\mathrm{Hg})$ (the weight gain) is much greater than in air. The decrease in the rate of formation of $\mathrm{ZnO}$ with time, however, is perceptible.

\section{Conclusions}

In principle, an electrochemical method should provide the requisite accuracy for the determination of the atomic weight of such elements as zinc, i.e., elements whose anodic behavior is such that they may be incorporated into a coulometric cell. Such operations as the accurate measurement of current, time, and mass pose no problem. Two practical problems, however, the fall-off of anode material during the passage of current, and the corrosion of the zinc anode required investigation in some depth. The incorporation of a membrane filter into the coulometric cell made possible measurements that show that anode fall-off is negligible during a typical coulometric experiment when an amalgamated zinc electrode is used. The corrosion of the amalgamated zinc anode is primarily a function of the concentration of air in the electrolyte. Deaeration of the electrolyte reduces this corrosion effect below the level of significance in the conducted coulometric experiments. This study paved the way for subsequent accurate determination of the electrochemical equivalent and the atomic weight of zinc, as described in the companion paper [26].

\section{References}

[1] International Commission on Atomic Weights, Comptes Rendus XXIV IUPAC Conference, Prague, 4 to 10 Sept. 1967, pp. 130-141.

[2] Cameron, E. A., and Wichers, E., J. Am. Chem. Soc., 84, 4175 (1962).

[3] Hönigschmid, O., and von Mack, M., Z. anorg. und Allgem. Chem., 246, 363 (1941).

[4] Baxter, G. P., and Grose, M. R., J. Am. Chem. Soc., 38, 868 (1916).

[5] Baxter, G. P., and Hodges, J. H., J. Am. Chem. Soc., 43, 1242 (1921). 
[6] Leland, W. T., and Nier, A. O.,Phys. Rev., 73, 1206 (1948).

[7] Hess, D. C., Inghram, M. G., and Hayden, R. J., Phys. Rev., 74, 1531 (1948).

[8] Shields, W. R., Craig, D. N., and Dibeler, V. H., J. Am. Chem. Soc., 82, 5033 (1960)

[9] Shields, W. R., Garner, E. L., and Dibeler, V. H., J. Res. Nat. Bur. Stand. (U.S.) 66A (Phys. and Chem.), No. 1, 1-3 (Jan.Feb. 1962).

[10] Shields, W. R., Murphy, T. J., Garner, E. L., and Dibeler, V. H. J. Am. Chem. Soc., 84, 1519 (1962).

[11] Shields, W. R., Murphy, T. J., and Garner, E. L., J. Res. Nat. Bur. Stand. (U.S.), 68A (Phys. and Chem.), No. 6, 589-592 (Nov.-Dec. 1964).

[12] Catanzaro, E. J., Murphy, T. J., Garner, E. L., and Shields, W. R., J. Res. Nat. Bur. Stand. (U.S.), 68A(Phys. and Chem.), No. 6, 593-599 (Nov.-Dec. 1964).

[13] Shields, W. R., Goldich, S. S., Garner, E. L., and Murphy, T. J., J. Geophys. Res., 70,479 (1965).

[14] Shields, W. R., Murphy, T. J., Catanzaro, E. J., and Garner, E. L., J. Res. Nat. Bur. Stand. (U.S.), 70A (Phys. and Chem.), No. 2, 193-197 (Mar--Apr. 1966)

[15] Catanzaro, E. J., Murphy, T. J., Garner, E. L., and Shields, W. R. J. Res. Nat. Bur. Stand. (U.S.), 70A (Phys. and Chem.), No. 6, 453-458 (Nov.-Dec. 1966).

[16] Laird, J. S., and Hulett, G. A., Trans. Am. Electrochem. Soc., 22, 385 (1913)

[17] Gladstone, J. H., and Hibbert, W., J. Chem. Soc., 55, 443 (1889).
[18] Hamer, W. J., J. Res. Nat. Bur. Stand. (U.S.), 72A (Phys. and Chem.), No. 4, 435-439 (July-Aug. 1968).

[19] Craig, D. N., Hoffman, J. I., Law, C. A., and Hamer, W. J., J. Res. Nat. Bur. Stand. (U.S.), 64A (Phys. and Chem.), No. 5, 381-402 (Sept.-Oct. 1960).

[20] Marinenko, G., and Taylor, J. K., Anal. Chem., 40, 1645 (1968).

[21] Hamer, W. J., Standard Cells. Their Construction, Maintenance, and Characteristics. Nat. Bur. Stand. (U.S.), Monogr. 84, 42 pages (June 1968).

[22] Thomas, J. L., Precision Resistors and Their Measurement, Nat. Bur. Stand. (U.S.), Circ. 470, 35 pages (Oct. 1948),

[23] Hodyman, C. D., and Holmes, H. N., eds., Handbook of Chemistry and Physics, Chemical Rubber Publishing Co., Cleveland, Ohio, 1943, p. 1867.

[24] Mancy, K. H., and Jaffe, T., Analysis of Dissolved Oxygen in Natural and Waste Waters, U.S. Department Health, Education and Welfare, Cincinnati, Ohio, 1966.

[25] Marinenko, G., and Foley, R. T., J. Res. Nat. Bur. Stand. (U.S.), $75 \mathbf{A}$ (Phys. and Chem.), No. 6, 561-564 (Nov.-Dec. 1971).

[26] Marinenko, G., and Foley, R. T., J. Res. Nat. Bur. Stand. (U.S.), 79A (Phys. and Chem.), No. 6, 745-757 (Nov.-Dec. 1975).

(Paper 70A6-871) 